\title{
Solutions for full-outdoor-air operation of air rooftop units with direct expansion circuit and integrated recirculation
}

\author{
Federico Pedranzini ${ }^{1 *}$, Lorenzo Cavina ${ }^{2}$, Andrea De Piccoli ${ }^{3}$, Damiano Rossi ${ }^{3}$ \\ ${ }^{I}$ Politecnico di Milano, Dipartimento di Energia 20154, Milano, Italy \\ ${ }^{2}$ Hera S.p.A, 40127 Bologna, Italy \\ ${ }^{3}$ Clivet S.p.A., 32032 Feltre (BL) Italy
}

\begin{abstract}
Following the advent of the Sars - Cov 2 pandemic, HVAC systems have been affected by different interventions both in the emergency and in the medium term. These interventions were dictated by the need to maximise the risk reduction within air-conditioned environments and among these interventions one of the most applied has been the elimination of recirculation in favor of a full-out-door- air operation, specifically in multi-zone systems.

Some plant, such as those served by roof-top units, however, provide a minimum share of recirculation that is necessary for the proper functioning of the integrated refrigeration unit. For these units, the elimination of recirculation has led to a significant increase in blocking situations.

The research provides the basis for the application of integrated solutions designed to prevent blocking situations for new and existing systems through the insertion of a modulated bypass between the supply air and the external air intake so as to allow temporarily the recirculation function without, however, creating a situation of risk propagation. The proposed solutions have been applied to a real system, the regulation has been carried out in integration with the management logic of the unit and has been tested to be effective in cooling mode.
\end{abstract}

\section{Introduction}

Traditionally Rooftop Units (RTU) are used for all-air applications in large environments such as shopping malls, exhibition halls, cinemas and theatres. This type of solution is generally preferred by designers as it offers a compact, stand-alone solution that does not require water generators and ancillary hydraulic circuitry, and the absence of an intermediate fluid guarantees an improvement in the overall efficiency.

On the other hand, this type of units is less flexible and customizable from the point of view of application as it derives from mass production, although the product range is generally sufficiently wide.

A further advantage of this type of system consists in the fact that the heating and cooling power generation system is integrated with the user system, i.e. the air treatment section; this allows, in the more advanced versions, a series of optimizations at the control level that can

\footnotetext{
*Corresponding author: federico.pedranzini@polimi.it
} 
involve the management of the fans according to the specific operating situations, with specific reference to defrosting situations in heating mode as well to the situations of full operation.

The critical aspect of the integrated solutions arises mainly from the fact that the load is represented only by the air treatment, which is typically a user characterized by dynamics and transients that are sometimes sudden and that can put the control of the refrigeration circuit in difficulty; furthermore, it must be considered that the advent of variable speed systems has made the control issue even more complex.

The analysis of the operation of rooftop units under different load conditions has been developed by the manufacturers in order to optimize the performance and protect the units from the risk of downtime or malfunction. The combination of a refrigeration unit and an air handling unit makes the system subject to a wide variety of parameters and operating combinations that are unsuitable for the development of simplified control models both from the point of view of fault detection (Ebrahimifakhar et al. , 2020 [1]) and from the point of view of energy performance evaluation and control (J. Cai, et al. 2018 - W.Wang et al. , 2019 [2-3]). The strategies adopted are mainly related to the use of statistically based data analysis and the most advanced implementations adopt table-based logics. Unlike systems based on chillers and hydraulic circuits, these systems do not and cannot have inertial storage elements (circuit water content or storage tanks) capable of stabilizing the load on the generator side. It is well known that vapor compression refrigeration circuits are, from the point of view of control, particularly sensitive to sudden changes in the load which cause abrupt changes in the exchange conditions at both the condenser and the evaporator with potentially dangerous consequences for the integrity of the components (for example the possible entry of liquid into the compressor).

A further critical element can be represented by the exceeding of the design temperatures at the treatment inlet and therefore of the powers required on the evaporator or condenser side depending on whether cooling or heating is being used. In such situations the exchange conditions can lead not only to a drastic drop in yield but also to problems linked to the control of the operating pressures which generally lead to a stoppage of the machine or a limitation of operation in order to avoid problems with the components.

In the absence of the stabilizing element guaranteed by a large enough water content, the systems integrated in the rooftop require the adoption of solutions suitable for attenuating sudden variations in load.

Among the solutions adopted by the manufacturers, the most important is the adoption of a minimum air recirculation, the entity of which can be bigger or smaller depending on the size and the level of sophistication of the refrigeration circuit control. Usually, manufacturers define classes of RTU capable of operating with more or less recirculation with a minimum of $20 \%$. The recirculation rate can be further reduced by oversizing the unit, but this can lead to lower efficiency values at nominal operating rate.

The presence of inherent recirculation within this type of unit turned out to be critical with the advent of the Sars Cov-2 pandemic. The risk of cross-contamination of the environments due to the presence of recirculation without effective pollutants removal was immediately considered to be significant for multi-zone systems. For this reason, national (Aicarr 2020 [4-5] and international (REHEVA 2021 [6]) guidelines issued by governments, while agreeing on the obvious usefulness of mechanical ventilation systems, have indicated the elimination of recirculation as an urgent measure for all existing systems where cross contamination is possible.

This measure has had a different impact depending on the type of system and has had consequences in terms of performance as well as energy. 
In the case of rooftops, however, turning off the recirculation can potentially lead to a considerable increase in the frequency of downtime or limitation situations for the reasons listed above.

For this reason, measures have been identified to prevent such situations, with the characteristic of being able to be applied externally to the machine, in order to allow a mode of operation that temporarily reduces performance to enable full-air operation without functional inconvenience.

These solutions also preserve the choice of rooftop systems in consideration of possible further emergency situations which designers will have to consider in the future.

\section{Typical layout of Rooftop Units.}

The typical layout of the RTU installed and actually on the market is shown in Figure 1.

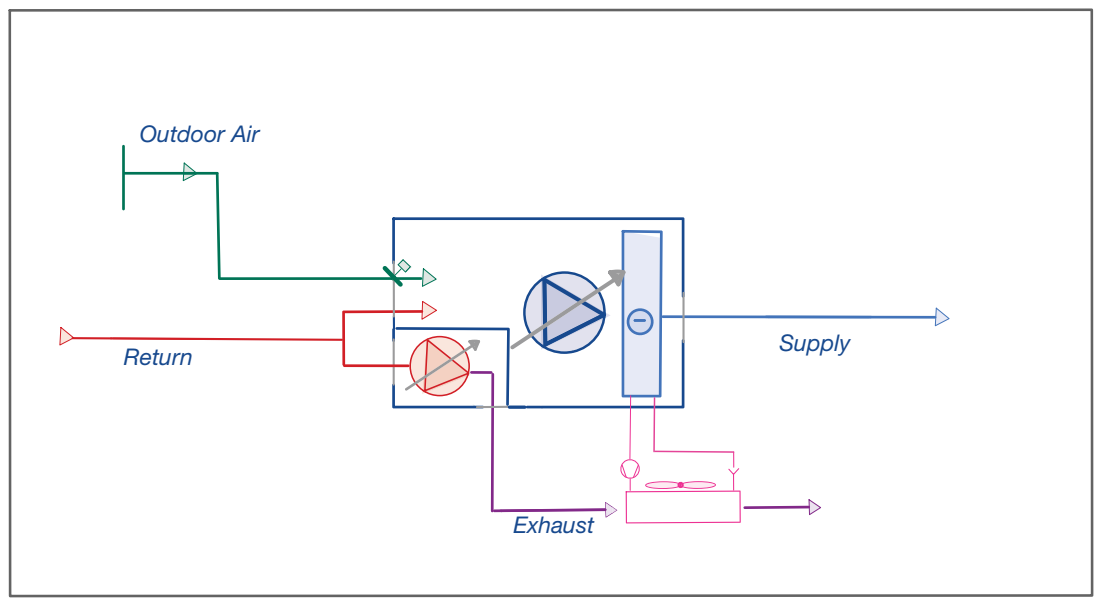

Fig. 1. Typical layout of a rooftop unit.

These units are generally equipped with two fans, one supply and one exhaust fan. The supply fan works together with the exhaust fan to provide the necessary head for the return. The outdoor air intake is fitted with a motor-driven damper and the co-ordination action between the expulsion fan and the position of the outdoor air damper allows the level of mixing between the two air flows to be modulated as required.

Generally, and as can be seen in the figure, there is no physical separation to prevent the return air from mixing with the external air, for this reason a certain amount of recirculation is intrinsically visible during the nominal functioning. This amount of recirculated air will therefore depend on the operating conditions of the exhaust fan, the outdoor air damper, the pressure drops along the return air path and the outdoor air intake.

From the point of view of the RTU embedded controller, recirculation is therefore defined on the basis of the requirements of the unit or, more precisely, on the basis of the operating conditions of the integrated cooling unit. Generally speaking, the control will ensure that recirculation is increased in all those situations in which the internal loads or external air situations are such as to risk some pressure drift phenomena within the refrigeration cycle that can result in precautionary blocking situations.

\section{The proposed strategy}


The idea behind this hypothesis is based on the replacing the recirculation of the return air with a bypass located between the supply air and the return air section in the machine, replacing the need for recirculation of the ambient air and therefore preventing any possible cross contamination.

At the same time as inserting the bypass branch, a motorized damper (on-off, non-modulating type) is installed to prevent the recirculation air from entering the machine, keeping the return air duct connected exclusively to the exhaust fan.

The proposed solution is illustrated in figure 2 .

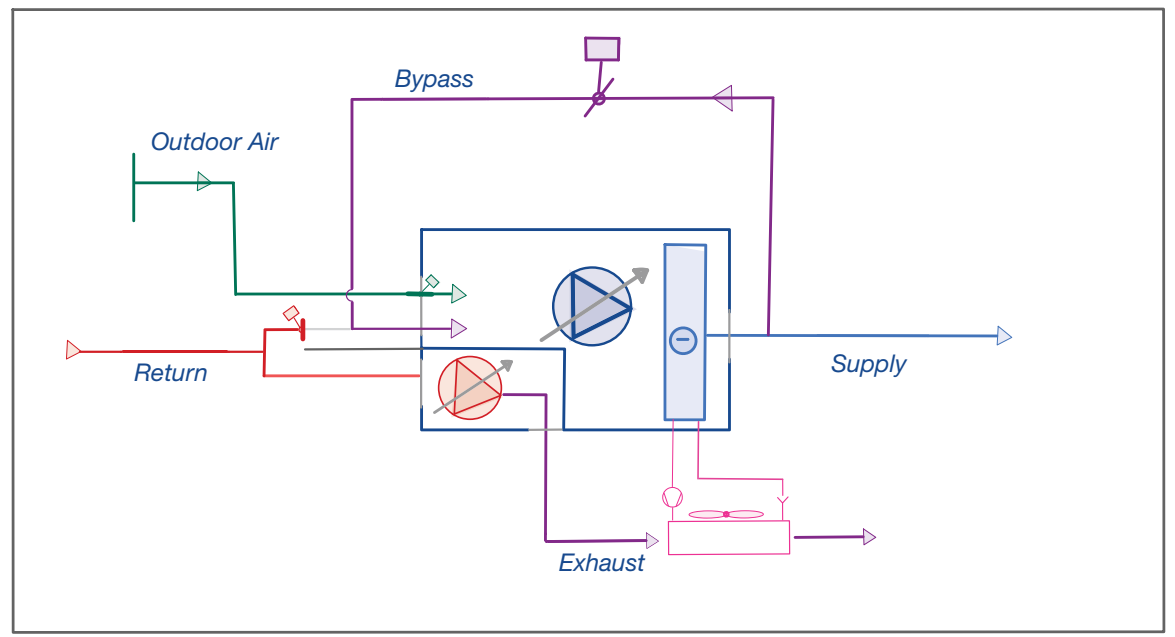

Fig.2. Typical layout of a rooftop unit with integration of the bypass branch

With regard to the amount of air sent to the environment, the effect is to guarantee a supply flow made of only external air and reduced by the bypassed part. The mixture coming at the treatment section is no longer made up of ambient air plus external air, but bypassed air at the supply conditions together with external air.

The control appears to be very simple as it is a matter of managing the temperature of the mixed air at the inlet simply by taking into account that the external air will be mixed with bypassed supply air rather than recirculated ambient air.

The supply air compared to the environment is at a lower temperature in cooling and a higher temperature in heating, which is why in order to control the mixed temperature, the bypassed air will be in smaller volume than the previously recirculated.

At a first analysis it may be interesting and immediate to adopt a temperature control which acts on the bypass damper with direct control of the mixed temperature, however a more careful consideration suggests that this control mode may have some disadvantages.

The first disadvantage to be considered is that when the operating point of the cooling unit varies, the supply temperature undergoes changes which can be not negligible as well as sudden. In a control based on a temperature probe on the mixed air this involves the dependence of the damper position on the supply temperature, but the supply temperature is dependent itself on the operating point of the cooling unit which is to be preserved: in some way the regulated quantity influences retroactively one of the regulating quantities and this fact can lead to situations of pendulum and instability.

It has therefore been decided to pursue a logic of indirect control based on the principle that the trend of the load to which the cooling circuit is subjected depends mainly on the trend of the external air temperature. 
Consequently, it has been decided to make the proportion of bypassed air depend exclusively on the outdoor air temperature as this is an external quantity which cannot be influenced by the operation of the system but is directly correlated to the trend of the loads.

This choice also allows the implementation of an independent control which does not require an integration with the rooftop controller and makes the solution much more applicable to existing situations.

The sizing of the bypass branch is carried out by assuming reference temperatures that depend on the location as far as the outside air is concerned (presumably the conditions used in the design phase), supply temperatures considered respectively equal to $15^{\circ} \mathrm{C}$ in cooling and $30^{\circ} \mathrm{C}$ in heating, as well as the limit temperatures at the treatment inlet.

These temperature values are determined considering the exchange temperatures (and working pressure - refrigerant side) of the evaporator and definitively affected by the characteristics of the fluid used and by the sizing of the exchangers.

\subsection{Control logic}

Given that the operating situation being investigated is characterized by the need to run the system with all external air, the recirculation damper is always kept closed unless there are particular situations that will be specified later (e.g. start-up).

With reference to the summer operating conditions, in conditions of load lower than the nominal value with outdoor temperature not exceeding $30^{\circ} \mathrm{C}$, there is no reason to insert the bypass and the system can operate at nominal capacity. The only due check refers to the size of the outdoor air intake and the current consumption of the main fan.

When the external temperature exceeds $30^{\circ} \mathrm{C}$ the controller starts to activate the bypass with the logic illustrated in figure 3. A linear control from the null value leads to the maximum flow rate in correspondence with the temperature adopted as a reference in the sizing phase (ex. $\left.34^{\circ} \mathrm{C}\right)$.

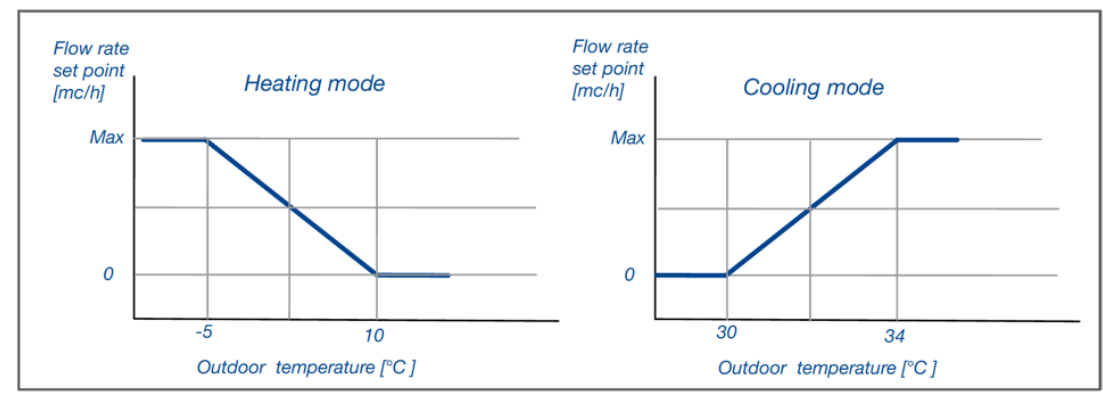

Fig. 3. Control logic of bypass flow rate depending on outside temperature.

Figure 3 shows the proposed control logic in both cooling and heating modes. In the latter case the control triggers $\mathrm{ON}$ when the external temperature falls below $10^{\circ} \mathrm{C}$ and proceeds linearly until the temperature reaches $-5^{\circ} \mathrm{C}$.

The calculation of the mixture temperature shows that in summer mode, imposing a maximum bypass flow rate equal to $26 \%$ and regulated as indicated, the temperature of the mixed air at the inlet of the treatment is maintained below $30^{\circ}$ up to an external temperature value of $35^{\circ} \mathrm{C}$.

In winter, imposing the same maximum bypass flow rate of $26 \%$, the mixed air at the inlet of the treatment is maintained above $3.5^{\circ} \mathrm{C}$ up to an external temperature of $-5^{\circ} \mathrm{C}$. 


\subsection{Bypass flow rate control}

The modulation of the flow rate on the bypass cannot be achieved by acting directly on the position of the damper, as the characteristic curve of the damper is not linear and would in any case depend on the pressure difference imposed by the supply fan as well as on the aeraulic resistance of the path competing with the bypass branch, which is represented by the whole supply system.

It was therefore considered necessary to make this regulation independent of the system context by adopting a $\mathrm{VaV}$ box with direct control of the flow rate by means of an on-board meter (Figure 4). The linearity of the behaviour is therefore ensured by the linear variation of the set point of the bypassed flow rate.

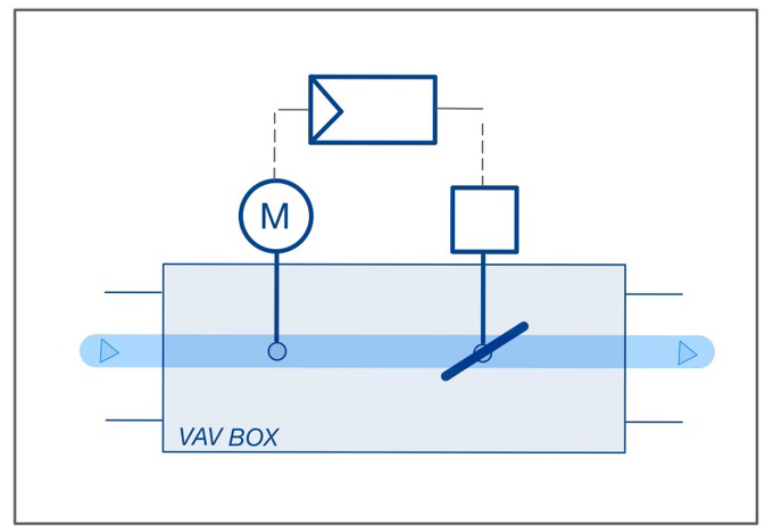

Fig.4. Principle scheme of a VAV (Variable Air Volume) box.

For functional opportunities, the activation of the control is conditioned to the operating status of the compressor, deactivating it if it is not operating.

\subsection{Start-up}

The system's start-up conditions are conditions in which the required power generation is maximum. In order to facilitate start-up in a short period of time (usually about ten minutes) the system can be operated in full recirculation mode by closing the outside air damper and stopping the exhaust fan. This condition introduces the risk of cross contamination. If, however, the contamination is associated with the presence of people (as is the case with the risk of infection by Covid-19), it is possible to plan the start-up phase in such a way that it is completed before the start of occupancy hours.

\subsection{Defrosting}

The defrosting condition is typical of Heat Pump operation and involves a temporary interruption of fan operation and a reversal of the refrigeration circuit.

This results in an interruption of ventilation and a consequent reduction in the renewal capacity but does not entail functional changes related to air flows and/or the introduction of a situation of possible recirculation.

\section{Experimental validation on a case study}


The solution proposed in this article was tested on a case study and measurements were taken during the month of June 2021 on a very recently installed rooftop unit serving a conference room at a facility in Ferrara, Emilia Romagna, Northern Italy.

It is a model Clivet CKN-XHE2i 10.1 unit that integrates an R-410A circuit with inverterdriven scroll compressor. The RTU can process a flow rate within the range of $4300 \div 6800 \mathrm{~m}^{3} / \mathrm{h}$, which by design has been set at $6000 \mathrm{~m}^{3} / \mathrm{h}$. The declared sensible cooling capacity is $24.6 \mathrm{~kW}(30,4 \mathrm{~kW}$ total cooling capacity) and the declared capacity in heating mode is $29.8 \mathrm{~kW}$. The declared data refer to operating conditions with $30 \%$ external air. The unit, according to the manufacturer's specifications, has been optimized for use with up to $50 \%$ external air. The reference external design summer conditions for operation of the unit are $34^{\circ} \mathrm{C}$ with $50 \%$ relative humidity.

On the basis of the data illustrated above and following the type of control proposed, it has been decided to size the bypass in such a way as to guarantee a maximum mixed temperature of $30^{\circ} \mathrm{C}$ in summer $\left(34^{\circ} \mathrm{C}\right.$ outside - depending on the location) and a minimum mixed temperature of $10^{\circ} \mathrm{C}$ in winter $\left(-5^{\circ} \mathrm{C}\right.$ outside - depending on the location) taking into account flow temperatures of $15^{\circ} \mathrm{C}$ and $30^{\circ} \mathrm{C}$ respectively.

The simple calculation of a flowrate and power balance leads to sizing the aumont to be bypassed at $26 \%$ of the flow rate in order to guarantee compliance with the limits, therefore the bypass damper has been initially set for a control to a maximum flow rate of $1560 \mathrm{~m}^{3} / \mathrm{h}$. The same value of bypass flow rate in winter mode guarantees a mixture temperature at the treatment inlet of $10^{\circ} \mathrm{C}$ up to an external temperature of $+3^{\circ} \mathrm{C}$.

\subsection{Implementation of control logic}

The general control of the system is carried out by the unit's controller and has not been modified.

The VAV box is a Systemair with Belimo LMV-D3_MP-F SYS controller with Belimo D3 sensor, dynamic measurement principle.

A Schneider Zelio SR3B101BD controller with SR3XT43BD analog extension equipped with a 3-wire PT100 temperature probe input and 0-10VDC analogue output suitable for controlling the setpoint of the $\mathrm{VaV}$ box was used to control the bypass system.

The Zelio Controller has been programmed scheme as shown in figure 3, with addition of comparison modules for the determination of the bypass activation temperature ranges and the presence of the gain modules properly set.

Since the full external air mode requires that the exhaust fan is able to elaborate the entire return flow rate a check was made of the pressure drops of the return ducts network.

The setpoint used for the activation of the bypass branch is $30^{\circ} \mathrm{C}$ (figure 3 ) and the maximum bypass flow rate has been initially considered equal to $26 \%$ of the nominal machine flow rate. The bypass branch was sized on the basis of this flow rate value. The control activation thresholds were set using hysteresis logic with a dead band of $+/-0.5^{\circ} \mathrm{C}$.

\subsection{Acquisition and monitoring system.}

Since the basic functionality of the all-air system is associated with both the maintenance of air quality and the control of comfort conditions, it was decided to monitor the main quantities, i.e. the flow of external air into the room and the thermal power (measured in cooling) expressed by the system during the monitored period.

In order to verify the control introduced, data loggers (Testo $174 \mathrm{H}$ with temperature and humidity sensor (accuracy $\pm 0.5^{\circ} \mathrm{C}$ and $\pm 3 \% \mathrm{RH}$ ) were inserted at the outside air intake and at the outlet of the supply fan. In addition, a temperature recorder was installed inside the unit between the fan and the treatment section. The unit is also equipped with an on-board 
flow rate supply measurement system and by difference with the bypass flow rate (the value of which has been verified to be consistent with the setpoint value of the VAV box) it is possible to obtain an estimate of the flow rate sent to the conditioned space.

Further quantities monitored throughout the test are the compressor rotation frequency and the compressor discharge temperature. The defrosting scenario was not considered due to the period in which the test was conducted. The general summary of the acquisition system, of the quantities acquired by direct measurement, of the quantities acquired by the control system and of the quantities obtained indirectly from the previous ones is shown in Table 1 and Table 2. The quantities were acquired with a sampling frequency of 1 minute.

Table 1: Measured quantities by probes specifically installed for monitoring.

\begin{tabular}{|c|c|c|c|c|}
\hline Tag & Quantity & Type & Sample Rate & Accuracy \\
\hline $\mathrm{T}_{\mathrm{OD}}$ & $\begin{array}{l}\text { Outdoor Air Temperature } \\
{\left[{ }^{\circ} \mathrm{C}\right]}\end{array}$ & measured & $60 \mathrm{sec}$ & $0,5^{\circ} \mathrm{C}$ \\
\hline $\mathrm{T}_{\mathrm{S}}$ & $\begin{array}{c}\text { Supply Air Temperature } \\
{\left[{ }^{\circ} \mathrm{C}\right]} \\
\end{array}$ & measured & $60 \mathrm{sec}$ & $0,5^{\circ} \mathrm{C}$ \\
\hline $\mathrm{T}_{\mathrm{R}}$ & Return Air Temperature $\left[{ }^{\circ} \mathrm{C}\right]$ & measured & $60 \mathrm{sec}$ & $0,5^{\circ} \mathrm{C}$ \\
\hline $\mathrm{T}_{\mathrm{M}}$ & Mixed Air Temperature $\left[{ }^{\circ} \mathrm{C}\right]$ & measured & $60 \mathrm{sec}$ & $0,5^{\circ} \mathrm{C}$ \\
\hline $\mathrm{RH} \% \mathrm{OD}$ & $\begin{array}{c}\text { Outdoor Air Relative } \\
\text { Humidity [\%] }\end{array}$ & measured & $60 \mathrm{sec}$ & $3 \%$ \\
\hline $\mathrm{RH} \% \mathrm{~s}$ & $\begin{array}{c}\text { Supply Air Relative } \\
\text { Humidity [\%] }\end{array}$ & measured & $60 \mathrm{sec}$ & $3 \%$ \\
\hline $\mathrm{RH} \% \mathrm{R}$ & $\begin{array}{l}\text { Return Air Relative } \\
\text { Humidity [\%] }\end{array}$ & measured & $60 \mathrm{sec}$ & $3 \%$ \\
\hline
\end{tabular}

Table 2. Quantities acquired by the control unit and calculated quantities.

\begin{tabular}{|c|c|c|}
\hline Tag & Quantity & Type \\
\hline $\mathrm{M}_{\mathrm{BP}}$ & Bypass Flow Rate $\left[\mathrm{kg} \mathrm{s}^{-1}\right]$ & Acquired From VAV Box Setpoint \\
\hline $\mathrm{M}_{\mathrm{SF}}$ & Supply Fan Flow Rate $\left[\mathrm{kg} \mathrm{s}^{-1}\right]$ & Acquired From RTU Controller \\
\hline $\mathrm{T}_{\mathrm{DISC}}$ & Discharge Temperature $\left[{ }^{\circ} \mathrm{C}\right]$ & Acquired From RTU Controller \\
\hline $\mathrm{V}_{\text {СOMP }}$ & $\begin{array}{c}\text { Compressor working frequency } \\
{[\mathrm{Hz}]}\end{array}$ & Acquired From RTU Controller \\
\hline $\mathrm{P}_{\mathrm{REC}}$ & $\begin{array}{c}\text { Recirculation Damper Position } \\
\text { [ON-OFF }]\end{array}$ & Acquired From RTU Controller \\
\hline $\mathrm{P}_{\mathrm{OD}}$ & Outdoor Air Damper Position [\%] & Acquired From RTU Controller \\
\hline $\mathrm{RH} \% \mathrm{M}$ & Mixed Air Relative Humidity [\%] & 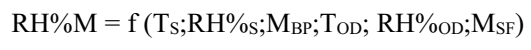 \\
\hline $\mathrm{h}_{\mathrm{S}}$ & Supply Air Enthalpy $\left[\mathrm{kJ} \mathrm{Kg}^{-1} \mathrm{~K}^{-1}\right]$ & $\mathrm{h}_{\mathrm{S}}=\mathrm{f}\left(\mathrm{T}_{\mathrm{S}} ; \mathrm{RH} \% \mathrm{~s}\right)$ \\
\hline
\end{tabular}




\begin{tabular}{|c|c|c|}
\hline $\mathrm{h}_{\mathrm{R}}$ & Return Air Enthalpy $\left[\mathrm{kJ} \mathrm{Kg}^{-1} \mathrm{~K}^{-1}\right]$ & $\mathrm{h}_{\mathrm{R}}=\mathrm{f}\left(\mathrm{T}_{\mathrm{R}} ; \mathrm{RH} \% \mathrm{R}\right)$ \\
\hline $\mathrm{h}_{\mathrm{M}}$ & Mixed Air Enthalpy $\left[\mathrm{kJ} \mathrm{Kg}^{-1} \mathrm{~K}^{-1}\right]$ & $\mathrm{h}_{\mathrm{M}}=\mathrm{f}\left(\mathrm{T}_{\mathrm{M}} ; \mathrm{RH} \% \mathrm{M}\right)$ \\
\hline $\mathrm{M}_{\mathrm{S}}$ & $\begin{array}{c}\text { Flow Rate delivered To Space }[\mathrm{kg} \\
\left.\mathrm{s}^{-1}\right]\end{array}$ & $\mathrm{M}_{\mathrm{S}}=\mathrm{f}\left(\mathrm{M}_{\mathrm{SF}} ; \mathrm{M}_{\mathrm{BP}}\right)$ \\
\hline $\mathrm{Q}_{\mathrm{CC}}$ & Cooling Coil Power $[\mathrm{kW}]$ & $\mathrm{QCC}=\mathrm{f}\left(\mathrm{M}_{\mathrm{SF}} ; \mathrm{h}_{\mathrm{S}} ; \mathrm{h}_{\mathrm{M}}\right)$ \\
\hline
\end{tabular}

Humidity ratio, enthalpy and specific volume values needed for the calculation of the cooling capacity were calculated from the temperature and humidity measurements, with reference to a standard atmospheric pressure (Ferrara, Italy - 9m on the sea level).

Figure 5 shows the layout of the probes inserted and the reference of the quantities acquired.

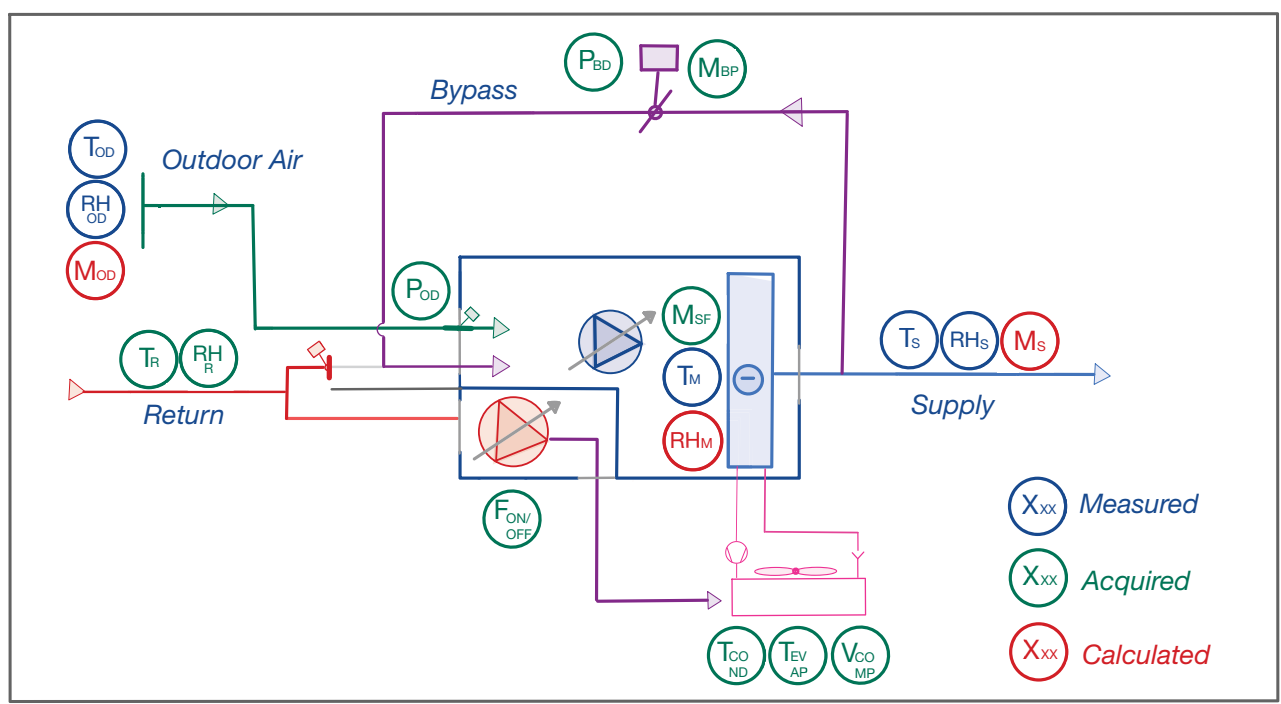

Fig. 5. Arrangement of probes and references to acquired and calculated quantities.

\section{Results.}

The tests were conducted during the month of June 2021, and the unit was made to work under outdoor conditions suitable for testing the proposed solution.

The tracking on some consecutive days was analyzed in terms of external temperature and in terms of system performance. Figure 6 shows the trends on the days that were considered representative from the point of view of evaluating the effectiveness of the solution introduced. 


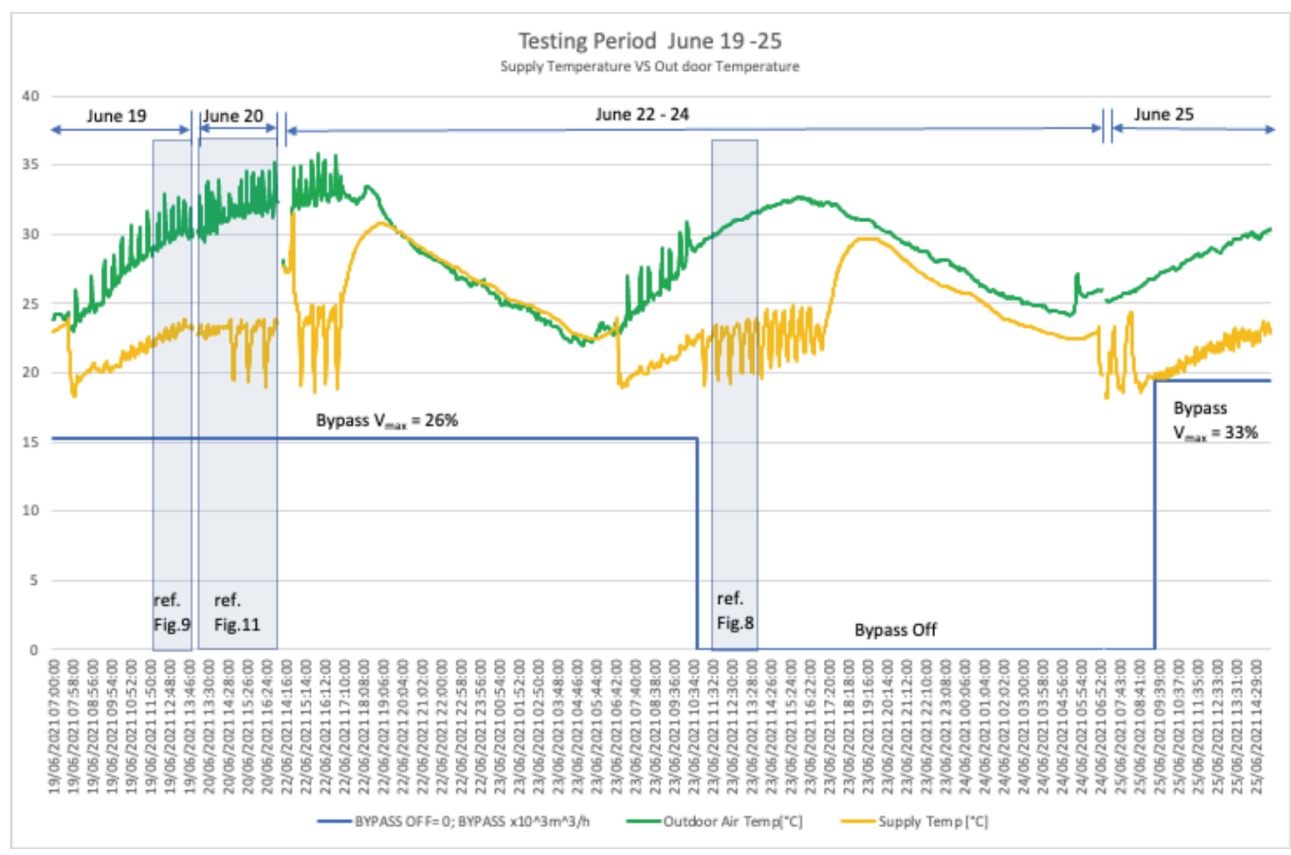

Fig. 6. Representation of the external and delivery temperatures during the test period. The setting conditions of the bypass control are shown. The boxes for the time periods are shown in detail in Figures 8,9 and 11 .

In particular, the graph is shown for days that are very similar from the point of view of external temperatures with maximum values above $30^{\circ} \mathrm{C}$, in order to verify the performance of the intervention. The cases tested correspond to a reference situation with all external air and therefore in a situation which is very different from the normal operation foreseen by the manufacturer.

In the first case described, the bypass regulation was deactivated (Bypass Off), so as to highlight any regulation problems. In the second case presented the bypass regulation was activated (Bypass $V \max =26 \%$ ) and the system was able to use the system to be tested.

It can also be seen that in the first part of the measurement (until the moment of change between Bypass on 26\% and Bypass OFF) the temperature probe shows significant oscillations due to the presence of a cooling unit near the installation. In the second part of the graph the probe is repositioned and the signal relative to the external temperature is much more regular.

\subsection{Functioning without Bypass.}




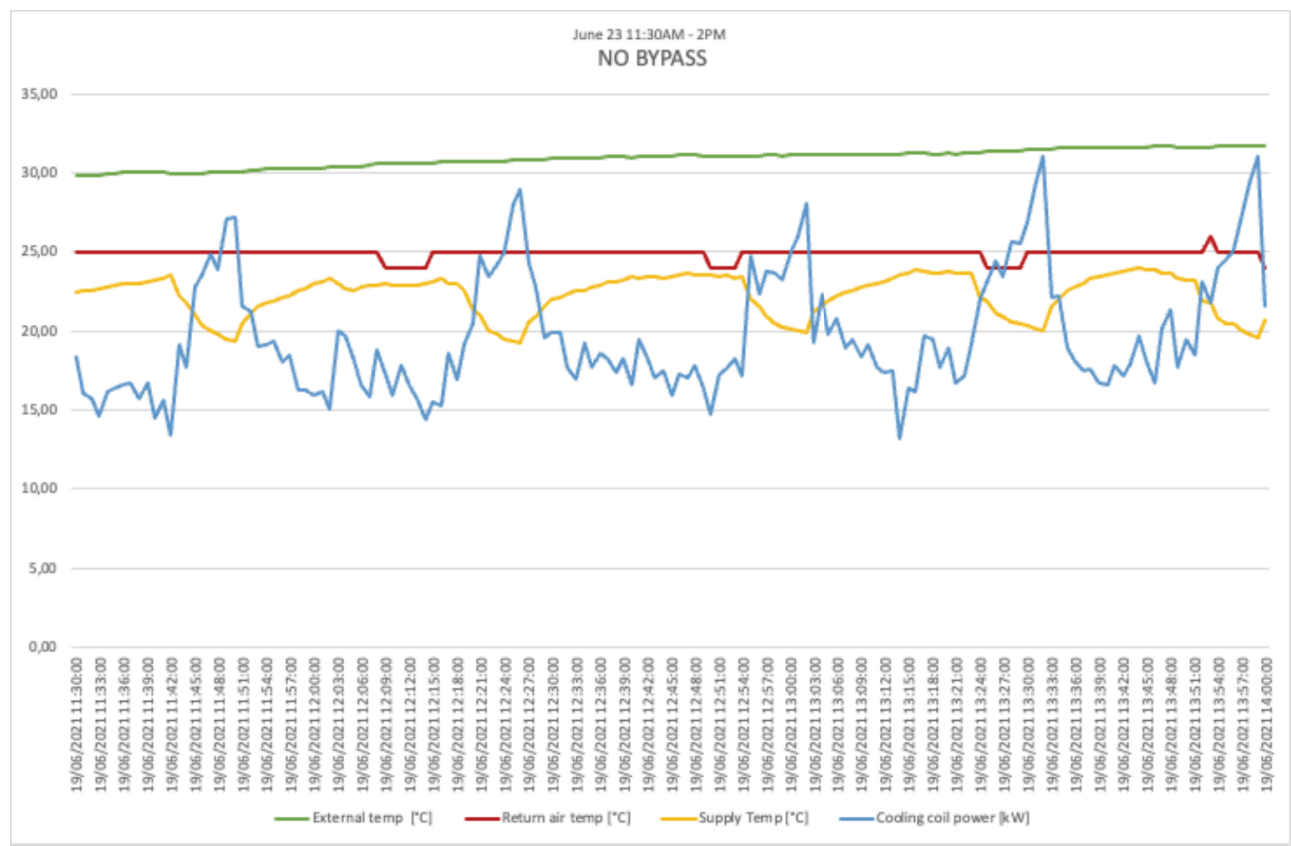

Fig. 7. Trend of the main parameters during operation without Bypass.

Figure 7 refers to the functioning with all external air and without Bypass recirculation that characterized the central part of the test period: it shows the trend of the measured and calculated quantities considered significant, such as the external temperature, the temperature of the air mixed with the bypass flow rate at the inlet of the treatment section, the delivery temperature, the cooling capacity to the exchanger.

In the operating condition without Bypass, the value of the flow rate delivered to the room corresponds to the value of the machine flow rate and is therefore kept almost constant by the control of the rooftop unit.

he evaluation of the behavior of the refrigeration unit takes on an almost cyclical pattern and it is noted that there is a periodic reduction in the power expressed, an indication that the internal regulation of the unit intervenes in order to protect the unit as described in the previous paragraphs.

The power output in general appears reduced compared to the manufacturer's data.

It should be noted that the dependence of the system operation on the external temperature is twofold since it affects both the exchange conditions of the evaporator with the air to be sent to the space and the working conditions of the air condensation section.

In this specific case, the connection between the machine, the system, and the $\mathrm{VaV}$ box has been made in such a way as to make it impossible to flush the condenser of the cooling unit with the exhaust air (at room temperature), and this has certainly penalized performance.

The increase in external temperature favors exchange in evaporation and penalizes exchange on the condenser: as this last factor is prevalent for the purposes of maintaining the refrigeration cycle within the design range, the RTU controller tends to partialize the compressor by reducing the flow of fluid to the condenser to allow suitable exchange even at high temperatures.

The result is a partialisation of the compressor and a reduction in the cooling power output which was observed throughout the tests.

In order to test the behavior of the unit in terms of performance and to limit the quantity of variables as much as possible, an ambient setpoint of $20^{\circ} \mathrm{C}$ was established for the entire 
duration of the tests, with the aim of forcing the unit to always provide maximum capacity according to the operating conditions of the refrigeration circuit.

In the test conditions shown in the figure, it can be seen that the average power supplied oscillates around the value of $15 \mathrm{~kW}$, much of which is dedicated to the treatment of external air and only partially to the cooling effect of the environment. After treatment, the air is not sent into the room at the expected temperature of $15^{\circ} \mathrm{C}$, but at an average temperature of approximately $23^{\circ} \mathrm{C}$, with an effect that is however enough to maintain the temperature in the room at approximately $25-26^{\circ} \mathrm{C}$.

Lastly, the quality of the control and stability of the system is represented by the supply temperature trend, which is affected by the cyclical trend of the compressor and therefore sees oscillations and deviations in the order of $3-4^{\circ} \mathrm{C}$ with a periodicity of a few minutes. This effect translates into a potential comfort problem in the room.

\subsection{Operation with Bypass}

Figures 8,9 and 10 show the behavior of the RTU with bypass activated.

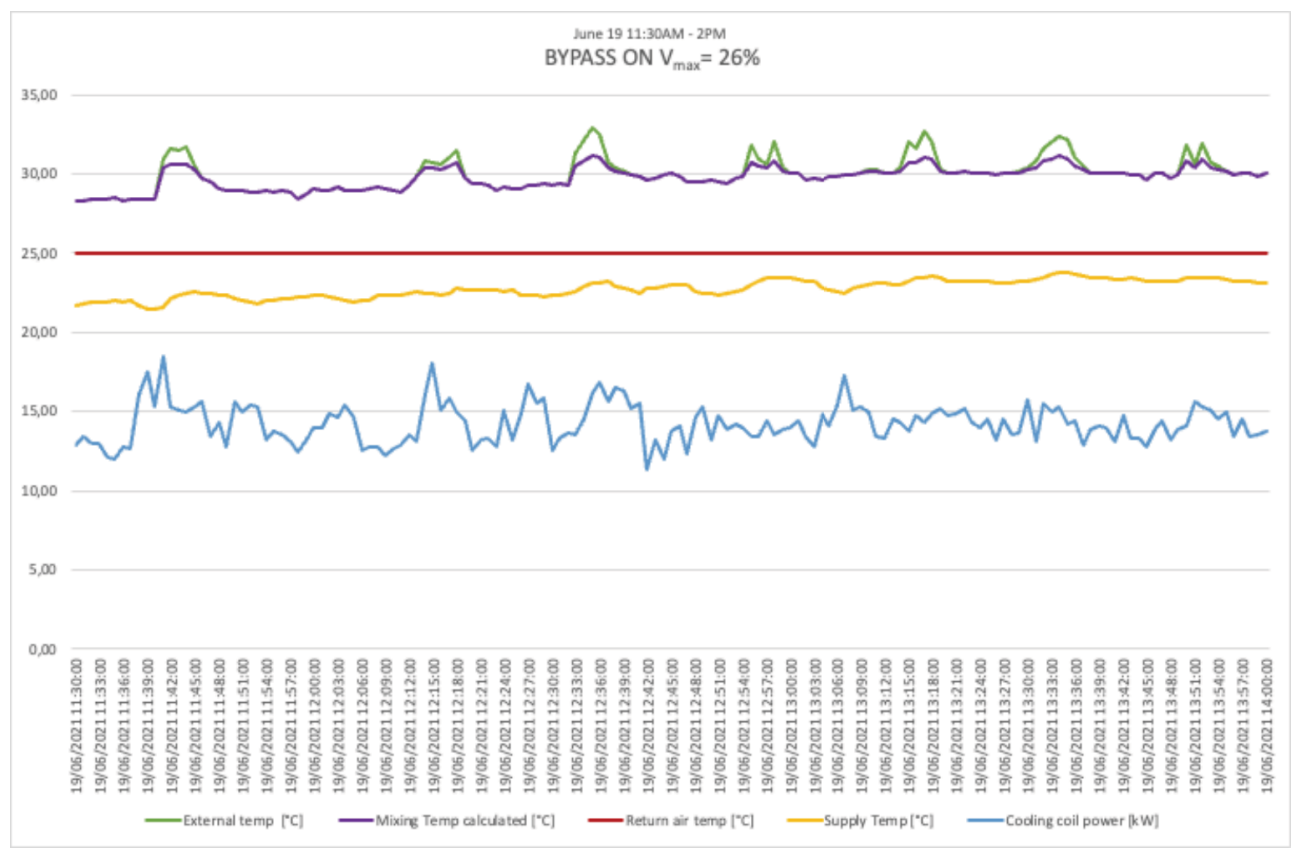

Fig. 8. Trend of the main parameters during operation with Bypass with external temperatures slightly above $30^{\circ} \mathrm{C}$.

The climatic situation represented in Figure 8 is characterized by the occasional presence of external temperature values above $30^{\circ} \mathrm{C}$, i.e. the threshold for the intervention of the regulation. What can be seen is the expected more regular behavior compared to the case without Bypass. The capacity delivered cannot be compared in absolute terms due to the different external temperatures at which the machine was operating in the two conditions, however it has also been seen that the compressor operating frequency differs from the previous case and is characterized by oscillations of a less wide amplitude. 
The stabilizing effect that is guaranteed by the recirculation rate during normal operation is recovered, and it can be seen that the inlet temperature is much more regular and free of sudden changes.

Figure 9 shows the trend of the fan, bypass and supply flow rates. The maximum reduction in the supply air has been deliberately limited in order not to compromise the correct operation of the diffusion system, which in this case is characterized by microperforated ducts.

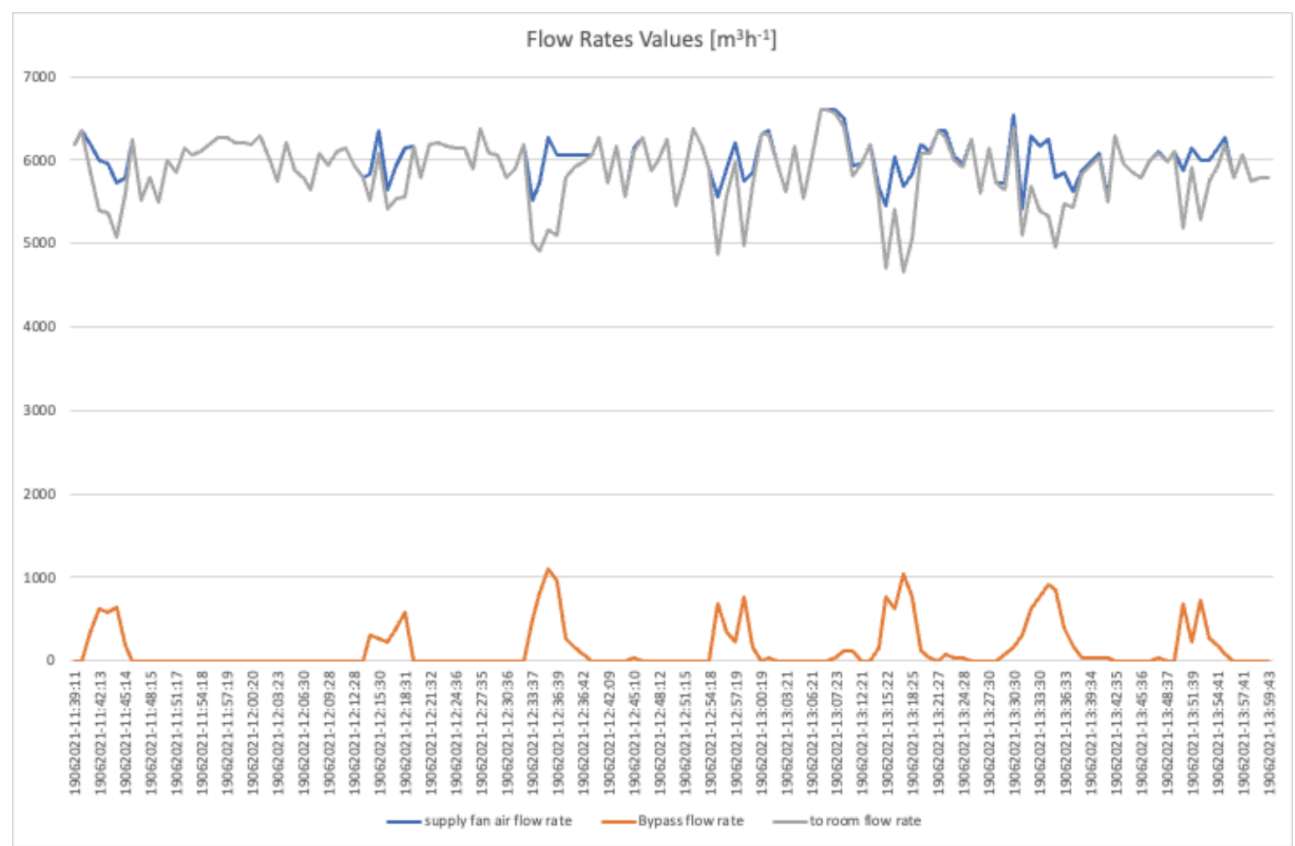

Fig. 9. Trend of flow rates controlled by VaV during operation with Bypass.

However, it can be considered that in this operating regime the supply temperature is attenuated by the power limitation of the unit and consequently the diffusion system, although working at lower flow rates can on the other hand be helped by a more limited temperature difference between supply and ambient.

The increase in the supply temperature due to the partialisation of the cooling circuit changes the reference temperatures that have been used to calculate the bypass flow rate.

The effect of this limitation results in the reduction of the external temperature range in which the Bypass protection is effective.

Fig. 6 shows how in the presence of temperatures above $32-33^{\circ} \mathrm{C}(20$ June) the action of the Bypass begins to be ineffective, and the behaviour becomes unstable. In Figure 10, this situation is represented more explicitly, and it can be seen that when a certain threshold of external temperature is exceeded the system begins to behave with the same dynamics of instability seen in the absence of the bypass. 


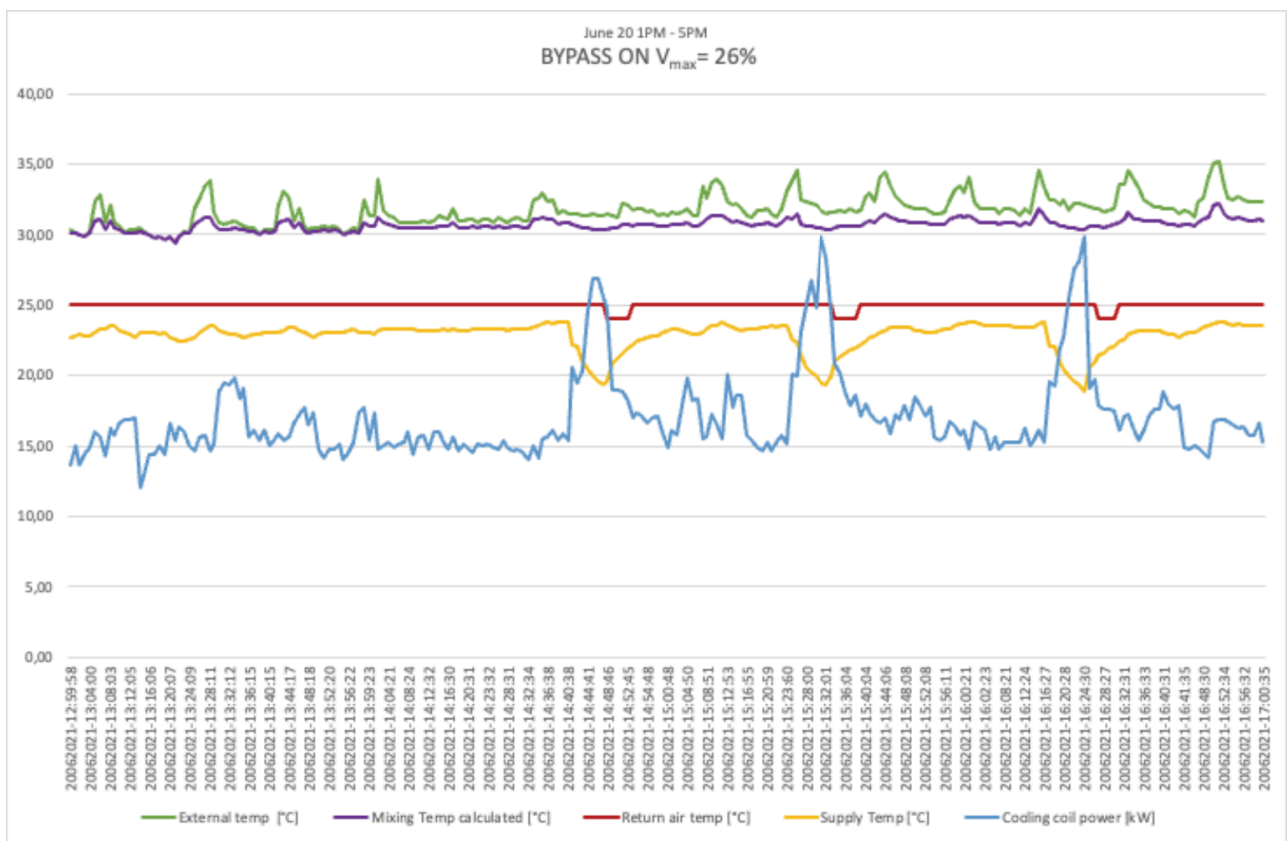

Fig. 10. Trend of the main parameters during operation with Bypass when the outdoor temperature of $32^{\circ} \mathrm{C}$ is exceeded.

In the final phase of the experiment, a third test was added for the purpose of evaluating the monitoring. In this test, the percentage of bypass flow rate was raised, bringing the maximum flow rate of the VAV box from $1530 \mathrm{~m}^{3} / \mathrm{h}$ to $1944 \mathrm{~m}^{3} / \mathrm{h}$, i.e. from $26 \%$ to $32.4 \%$ compared to the machine flow rate $\left(6000 \mathrm{~m}^{3} / \mathrm{h}\right)$.

The stabilization effect was also confirmed in this case as can be seen in Fig. 7 ( 25 June), although the temperatures were not such as to test the solution in a high load situation.

\section{Conclusions.}

The experimentation has highlighted how the condition of operation in full external air is actually a very critical condition, and that in the absence of an advanced control or appropriate measures the risk of machine downtime can increase considerably.

The unit used for testing is a unit equipped with the latest generation of controls and is therefore able to manage abnormal operating situations by partialising when necessary in order to safeguard the integrity of the components. In this specific case, therefore, the propensity of the unit to modify its behavior in critical conditions was evaluated. During the tests, even under the most critical conditions, the unit did not reach the precautionary stop.

The implementation of the proposed system was mainly aimed at achieving two results: the first was to recreate the stabilization effect offered by recirculation for a more regular behavior of the cooling unit.

The second objective, linked to the first, was to check whether the operating conditions guaranteed by the bypass were such as to allow the machine to work at a power closer to its rated power.

The results of the tests show that the first goal was achieved, as can be seen from the comparison of the load profiles of the compressor and the supply temperature. 
The second objective was only partially achieved, and this may depend on the limitation that was imposed on the maximum reduction of the flow rate towards the environment in order to protect the performance of the diffusion system.

The particular configuration of the connection realized has also deprived the condensation section of the possibility of using the expulsion air to obtain a more favorable operating condition.

As a consequence, the experimentation that has been carried out requires the variation of the ducts and dampers connection as well as a further experimental verification in winter mode with heat pump operation.

From the point of view of the applicability of the solution described, it is correct to specify that it is an alternative to the solutions that provide for an effective contaminants removal that can be recirculated in the environment. The bypass solution it is therefore a valid integration to the existing rooftop systems required to be able to operate also in a regime of all external air and whose sizing does not allow the insertion of suitable removal systems.

Finally, from the point of view of a sensible application, it is important to underline the fact that the use of exhaust air is fundamental to improve the exchange for condensation (and evaporation in the case of a heat pump). This allows the cooling circuit to work closer to the nominal power.

\section{References}

1. Amir Ebrahimifakhar, Adel Kabirikopaei, David Yuill. Data-driven fault detection and diagnosis for packaged rooftop units using statistical machine learning classification methods, Energy and Buildings, Volume 225, ISSN 0378-7788 (2020)

2. Jie Cai, James E. Braun. Assessments of variable-speed equipment for packaged rooftop units (RTUs) in the United States, Energy and Buildings, Volume 164, ISSN 0378-7788 (2018)

3. Weimin Wang, Srinivas Katipamula, Hung Ngo, Ronald Underhill. Energy performance evaluation of variable-speed packaged rooftop units using field measurements and building energy simulation, Energy and Buildings, Volume 183, ISSN 0378-7788 (2019)

4. AiCARR. Protocollo per la riduzione del rischio da diffusione del SARS-CoV2-19 mediante gli impianti di climatizzazione e ventilazione esistenti (2020)

5. AiCARR. 2020. Protocollo per la riduzione del rischio da diffusione del SARSCoV2-19 nelle operazioni di gestione e manutenzione degli impianti di climatizzazione e ventilazione esistenti (2020)

6. REHVA 2021. COVID-19 guidance document - How to operate HVAC and other building service systems to prevent the spread of the coronavirus (SARS-CoV-2) disease (COVID-19) in workplaces (2021) 